\title{
A study of detection, search, matching, and memory functions
}

M. S. MAYZNER, M. E. TRESSELT AND JAIMIE PEZENIK

NEW YORK UNIVERSITY

The present study develops an experimental paradigm designed to examine detection, search, matching, and memory functions as they relate to visual signal processing in man. Ss are presented with 2 lines of 10 letters each and required to detect a target letter common to both lines. The results clearly show the effects of display times and number of targets present with such a paradigm, and its usefulness in studying general problems of visual information processing is briefly, discussed.

Recent work by Estes (1965), Estes \& Wessel (1966), Neisser, Novick, \& Lazar (1963), and Sternberg (1967) all has been concerned with various aspects of visual signal processing by man. Estes has focused on problems of visual signal detection with random letter matrices under conditions of brief tachistoscopic exposures (i.e., $50 \mathrm{msec}$ ). Neisser, in contrast, has been concerned with signal search, where single or multiple signals (letters) are embedded in long random letter lists and the search is terminated when the target signal is located. Sternberg, adopting a third approach, has emphasized certain aspects of character recognition and matching as well as certain memory components which are implicated in the type of signal detection (or recognition) task which he has examined. In the oresent study a paradigm is developed and a first experiment is performed which incorporates certain elements of all of the earlier mentioned work and which it is hoped will provide some initial evidence relating detection, search, matching, and memory processing functions in a single composite experimental task. Method

The Ss were 40 undergraduate students from the Psychology Department of New York University and had participated in no previous studies in signal detection.

The basic experimental task was as follows: a card was displayed to $\mathrm{S}$ (employing a Gerbrands one-field tach) on which appeared two lines of 10 letters each, one line directly below the other (all letters were in caps), and $\mathrm{S}$ was instructed for different experimental conditions that he would have either $2,4,6$, or $8 \mathrm{sec}$ to locate and "call out" a target letter that appeared in both lines. One-hundred and sixty such cards were prepared, 80 cards with one target in both lines, and 80 cards with two targets in both lines as follows:

1 target $\begin{array}{r}\text { Z AQWESDXCF } \\ \text { EOLJMHYBVP }\end{array} \quad \begin{array}{r}\text { PTOUYREW targets } \\ \text { AZFGHJLTMK }\end{array}$

A 2 by 2 by 4 mixed analysis of variance design was employed (Winer, 1962, pp. 337-310). Factor A (two levels) consisted of the actual number of targets, either one or two. Factor B (two levels) consisted of the order in which different display times were presented, either $2,4,6$, and 8 sec or $8,6,4$, and 2 sec. Factor $\mathrm{C}$ (four levels) involved the display times employed, either $2,4,6$, or $8 \mathrm{sec}$. Ten Ss each were assigned randomly to each of the four conditions involved in Factors $A$ and $B$ with repeated measurements on Factor $C$. A given $S$ then received (for the four levels of Factor C) 20 cards with each card displayed for $2 \mathrm{sec}, 20$ cards with each card displayed for $4 \mathrm{sec}, 20$ cards with each card displayed for $6 \mathrm{sec}$, and 20 cards with each card displayed for $8 \mathrm{sec}$. Each of four groups of $10 \mathrm{Ss}$ received a total of 80 cards, Group $\mathrm{A}_{1} \mathrm{~B}_{2}$-one target, at 2, 4, 6 , and $8 \mathrm{sec}, \mathrm{G}$ roup $\mathrm{A}_{1} \mathrm{~B}_{1}$-one target, at $8,6,4$, and $2 \mathrm{sec}$, Group $\mathrm{A}_{2} \mathrm{~B}_{1}$-two targets, at $2,4,6$, and $8 \mathrm{sec}$, and Group $\mathrm{A}_{2} \mathrm{~B}_{2}$-two targets, at $8,6,4$, and $2 \mathrm{sec}$. The dependent response measure was the number of targets correctly identified in each of the 16 different experimental conditions, with a maximum score equal to 20 , since there were 20 cards per condition. Instructions were identical for all $40 \mathrm{Ss}$, in that they were told that a single letter was common to both lines on each card which they were to "call out" when they located it, within the time allowed; i.e., either $2,4,6$, or $8 \mathrm{sec}$ per card. No $\mathrm{S}$ ever realized in the two target conditions that a second target was present. Target locations were relatively equalized over the 10 positions in the top and bottom lines with the constraint that the target locations in each line always be separated by at least two other non-target letters, and each $S$ received his pack of 80 cards in a different random order. Target letters involved all 26 letters of the alphabet used with approximately equal frequency.

\section{Results and Discussion}

Table 1 presents the major findings of the study, showing Ms, Mds, SDs, and Rs of targets correctly identified for the 16 experimental conditions. Analysis of variance shows clearly that the one target vs two target condition (Factor $A$ ) was very significant ( $F=$ $66.0, \mathrm{df}=1 / 36, \mathrm{p}<.0001$ ), as well as the interaction of display times with the order in which the different display times were presented (Factor B by Factor C; $\mathrm{F}=98.0, \mathrm{df}=3 / 108, \mathrm{p}<.0001$ ). All other factors and interactions were nonsignificant at the $p<.01$ level. Since the $B$ by $C$ interaction was significant, the Friedman two-way analysis of variance by ranks test (Siegel, 1956, pp. 166-172) was applied to the four separate display time conditions, yielding highly significant effects: one target and $2,4,6$, and $8 \mathrm{sec}$ display times $\left(\chi_{\mathbf{r}}^{2}=15.24, p<.01\right)$; one target and 8 , 
Table 1. Targets Correctly Identified for the 16 Experimental Conditions of the Study.

\begin{tabular}{|c|c|c|c|c|c|c|c|c|c|c|c|}
\hline & & \multicolumn{10}{|c|}{ Display Times (in seconds) } \\
\hline & & $\underline{2}$ & 4 & 6 & $\underline{8}$ & Tot. & 8 & $\underline{6}$ & $\underline{4}$ & $\underline{2}$ & Tot. \\
\hline \multirow{4}{*}{1 Target } & $\mathbf{M}$ & 3.3 & 6.3 & 7.4 & 9.9 & 26.9 & 10.1 & 9.3 & 6.3 & 4.2 & 29.9 \\
\hline & Md & 4.0 & 6.5 & 8.0 & 10.0 & 28.0 & 10.0 & 9.0 & 7.0 & 4.5 & 30.5 \\
\hline & SD & 1.0 & 1.6 & 2.7 & 2.0 & 4.3 & 3.4 & 2.2 & 2.3 & 2.4 & 7.7 \\
\hline & $\mathrm{R}$ & $1-4$ & $3-9$ & $3-11$ & $6-13$ & $20-32$ & $5-16$ & $5-13$ & $3-10$ & $0-9$ & $19-44$ \\
\hline \multirow[b]{3}{*}{2 Targets } & M & 6.6 & 10.6 & 13.7 & 16.2 & 47.1 & 16.1 & 13.5 & 11.5 & 7.0 & 48.1 \\
\hline & $\mathrm{Md}$ & 6.0 & 11.5 & 12.0 & 17.0 & 48.5 & 16.0 & 13.5 & 11.5 & 6.5 & 48.5 \\
\hline & $\begin{array}{c}\mathrm{SD} \\
\mathrm{R}\end{array}$ & $\begin{array}{l}2.5 \\
412\end{array}$ & $\begin{array}{l}3.9 \\
5-18\end{array}$ & $\begin{array}{c}2.8 \\
11-18\end{array}$ & $\begin{array}{c}1.8 \\
13-18\end{array}$ & $\begin{array}{c}8.7 \\
35-59\end{array}$ & $\begin{array}{c}1.5 \\
13-19\end{array}$ & $\begin{array}{c}2.1 \\
10-17\end{array}$ & $\begin{array}{l}2.4 \\
6-14\end{array}$ & $\begin{array}{l}3.3 \\
1-12\end{array}$ & $\begin{array}{c}6.5 \\
40-58\end{array}$ \\
\hline
\end{tabular}

6,4 , and 2 sec display times $\left(\chi_{\mathbf{r}}^{2}=21.27, \mathrm{p}<.001\right)$; two targets and $2,4,6$, and 8 sec display times $\left(x_{\mathbf{r}}^{2}=23.97, p<.001\right) ;$ two targets and $8,6,4$, and $2 \mathrm{sec}$ display times ( $\underset{\mathbf{r}}{2}=26.37, \mathrm{p}<.001)$.

The results shown in Table 1 show quite clearly a consistent pattern of relationships. First, an increase from one target to two targets almost doubles the number of correct detections; second, as display time systematically increases in 2 sec increments, the number of correct detections increases in a relatively linear fashion; and third, the order in which display times are presented (i.e., 2, 4, 6, and $8 \mathrm{sec}$ or 8,6, 4 , and $2 \mathrm{sec}$ ) apparently has no effect whatsoever on the number of correct detections.

The implications of the above findings for visual information processing suggest that the above experimental paradigm may prove useful in studying detection, search, matching, and memory functions. As the task is presently constituted $\mathrm{S}$ is faced with the problem of potentially needing to make 100 matches or comparisons to detect the target signal. It is unlikely, however, that any $\mathrm{S}$ systematically attacks the task in this fashion, but rather scans back and forth in a perhaps random or quasi-random search pattern probably employing short-term storage of items just scanned to match against items that are to be scanned. Further work is currently in progress and being planned to dissect the various elements of the present paradigm into their respective functional and hopefully temporal components by varying the geometry of the display configuration, the content of the display items, the number of targets and non-targets present, etc., employing a more sensitive response index, namely, reaction time.

\section{References}

ESTES, W. K. A technique for assessing variability of perceptual span. Proc. Nat. Acad. Sci., 1965, 54, No. 2, 403-407.

ESTES, W. K., \& WESSEL, D. L. Reaction time in relation to display size and correctness of response in forced-choice visual signal detection. Percept. \& Psychophys., 1966, 1, 369-373.

NEISSER, U., NOVICK, R., \& LAZAR, R. Searching for ten targets simultaneously. Percept. mot. Skills, 1963, 17, 955-961.

SIEGEL, S. Nonparametric statistics for the behavioral sciences. New York: McGraw-Hill, 1956.

STERNBERG, S. Two operations in character recognition: Some evidence from reaction time measurements. Percept. \& Psychophys., 1967, 2, 45-53.

WINER, B. J. Statistical principles in experimental design. New York: McGraw-Hill, 1962. 